\title{
Smoking cessation among European older adults: the contributions of marital and employment transitions by gender
}

\author{
Sergi Trias-Llimós ${ }^{1} \cdot$ Magdalena M. Muszyńska $^{2} \cdot$ Antonio D. Cámara $^{3}$ • \\ Fanny Janssen ${ }^{1,4}$
}

Published online: 21 October 2016

(c) The Author(s) 2016. This article is published with open access at Springerlink.com

\begin{abstract}
Knowledge about the potential effects of stressful events on smoking cessation is helpful for the design of health interventions. Previous studies on this topic tended to group together adults of all ages and of both genders. We investigate the contribution of marital and employment losses on smoking cessation by gender, specifically among older adults in Europe. We used panel data from waves 4 (2011) and 5 (2013) of the Survey of Health, Ageing and Retirement in Europe for 3345 male and 3115 female smokers at baseline aged 50 and over from 13 countries. The associations between marital and
\end{abstract}

Responsible editor: D. J. H. Deeg

Electronic supplementary material The online version of this article (doi:10.1007/s10433-016-0401-4) contains supplementary material, which is available to authorized users.

Sergi Trias-Llimós

s.trias.1limos@rug.nl

Magdalena M. Muszyńska

mmuszyns@sgh.waw.pl

Antonio D. Cámara

adcamara@ujaen.es

Fanny Janssen

f.janssen@rug.nl

1 Population Research Centre, Faculty of Spatial Sciences, University of Groningen, Landleven 1, 9747 AD Groningen, The Netherlands

2 Institute of Statistics and Demography, Warsaw School of Economics, Al. Niepodległości 162, 02-554 Warsaw, Poland

3 Department of Business Management, Marketing and Sociology, University of Jaén, Campus de las Lagunillas, s/n Edificio D-3 (dep. 007), 23071 Jaén, Spain

4 Netherlands Interdisciplinary Demographic Institute, Lange Houtstraat 19, 2511 CV The Hague, The Netherlands employment losses and smoking cessation were derived from logistic regression models for each gender, controlling for age, educational attainment, diseases incidence and country of residence. Interactions between gender and marital and employment losses were tested. Over the analysed period, 119 smokers became widowed or divorced $(1.8 \%), 318$ became retired $(4.9 \%)$ and 100 became unemployed $(1.5 \%)$. Becoming widowed or divorced was associated with lower probability of smoking cessation among both men (OR 0.36, $95 \%$ CI 0.14-0.94) and women (OR 0.46, $95 \%$ CI 0.21-0.99). Transitions to unemployment and to retirement were not significantly associated with smoking cessation (OR $0.62,95 \% \mathrm{CI}$ 0.25-1.49; and OR 0.68, $95 \%$ CI 0.43-1.07, respectively). Gender differences in the association between marital and employment losses and smoking cessation were not statistically significant ( $p$ value $>0.05$ for all interactions). Health interventions should take into account that male and female older adults affected by marital loss are at risk of continuing smoking.

Keywords Stressful events - Smoking cessation · Older adults $\cdot$ SHARE $\cdot$ Europe

\section{Introduction}

Smoking is the leading risk factor in the burden of disease and mortality in Europe (Lim et al. 2012), and one of the most important public health issues in Europe. Assessing smoking cessation determinants is important because smoking cessation significantly improves people's health and reduces their mortality risk (Burns 2000; Doll et al. 2004; Taylor et al. 2002). Prior studies have shown that smoking cessation is consistently associated with 
demographic characteristics, such as sex and age; and that it is influenced by many factors that are amenable to change, including socio-economic factors, social support and the prevalence of smoking-related diseases (e.g. van den Putte et al. 2005; Broms et al. 2004; Margolis 2013; van Gool et al. 2007). Given the potential for changing many determinants of smoking cessation and the benefits of smoking cessation, gaining additional knowledge about the determinants of smoking cessation can aid policymakers aiming to improve public health by promoting smoking cessation.

Previous studies on the determinants of smoking cessation mainly focused on the role of socio-economic status, social support or psychosocial determinants in smoking cessation (e.g. Osler and Prescott 1998; Janzon et al. 2005), and paid less attention to the associations between key life course transitions and smoking cessation. The studies that investigated the role of key life course transitions found that smoking cessation is associated with both marital transitions (Giordano and Lindstrom 2011; Kriegbaum et al. 2011; Lee et al. 2005; Nystedt 2006) and employment transitions (Blakely et al. 2014; De Vogli and Santinello 2005; Giordano and Lindstrom 2011; Kriegbaum et al. 2011; Lang et al. 2007). These analyses also showed that marital loss and employment loss influence smoking cessation via stress (De Vogli and Santinello 2005; Falba et al. 2005; Johnson and Wu 2002; Thomas et al. 2005), which usually hinders efforts to quit. However, because most of these studies examined all adult age groups combined, little is known about the associations between key life transitions and smoking cessation among older adults. In analysing the determinants of smoking cessation, and specifically the role of marital and employment transitions, it is essential that older adults are studied separately (Jarvis et al. 2013) for a number of reasons. First, although the benefits of smoking cessation are greatest for smokers who quit early in life, quitting later in life is also associated with lower mortality (Doll et al. 2004; Taylor et al. 2002). Second, older adults are of special concern because they tend to need more health care than younger people, and because the number of older people in Europe is growing. Third, older adults are more likely to quit smoking than younger adults (Osler et al. 1999), largely because older adults are more likely than younger adults to suffer from various smoking-related diseases, which is regarded as a motivation to quit smoking (Margolis 2013; van Gool et al. 2007). Fourth, marital and employment loss, particularly widowhood and retirement, are prevalent at older ages. Fifth, the effects of various stressful events on smoking have been shown to differ over the life course (Grotvedt and Stavem 2005; Jarvis et al. 2013; Umberson et al. 2008; Whitson et al. 2006).
Although the importance of studying smoking cessation separately for different age groups has been acknowledged in the literature, the existing evidence regarding the importance of marital and employment losses to smoking cessation at older ages is both scarce and mixed. We are aware of only two studies that specifically examined smoking cessation among middle-aged and older adults in relation to marital transitions: one study that focused on female nurses (Lee et al. 2005), and another that looked at male health professionals (Eng et al. 2005); both in the US. These studies found that becoming widowed and remaining unmarried were associated with lower smoking cessation rates among these older women (Lee et al. 2005), but these transitions were not found to result in significant differences in smoking behaviour among older men (Eng et al. 2005). Although these studies observed some interesting potential gender differences, the narrowness of the selected group and settings affected the generalisability of the results.

In the literature on the association between employment transitions and smoking cessation, there has been mixed evidence regarding two of the main work-related transitions experienced by older adults: retirement and unemployment. For example, a British study found a positive association between retirement and smoking cessation (Lang et al. 2007). However, no such association was found in research conducted in the US (Midanik et al. 1995) or in the Netherlands (Henkens et al. 2008). Being unemployed was found to be negatively associated with smoking cessation in a study among British adults (Giordano and Lindstrom 2011), but the transition from being employed to being unemployed was not shown to be associated with lower chances of smoking cessation in the samples of older British (Falba et al. 2005) or German adults (Schunck and Rogge 2012).

Most of the previous studies on this topic did not distinguish between men and women. Yet the masking of gender differences could affect the overall results (Grotvedt and Stavem 2005). Only a few studies have reported gender-specific results among adults (McKee et al. 2003; Nystedt 2006). On the one hand, gender differences were not found in the association between marital disruption and smoking cessation (Nystedt 2006), or in the association between interpersonal loss and smoking behaviour (McKee et al. 2003). On the other hand, women were found to be less likely than men to quit smoking after financial or health events (McKee et al. 2003).

Various mechanisms are likely to affect the smoking cessation chances of men and women differently. Stress levels linked to marital and employment loss may not be the same for men and women, as men tend to report experiencing more work-related stressful events while women tend to report experiencing more interpersonal 
stressful events (Kendler et al. 2001). These gender differences may be due to differences between men and women in terms of their role configurations (Ensminger and Celentano 1990), and in their strategies for coping with stressful life course circumstances (Kessler and McLeod 1984). Furthermore, it is also well known that marriage has a more protective effect for men than for women in terms of the adoption of unhealthy behaviours (Schone and Weinick 1998), adverse health outcomes and even mortality (Lillard and Panis 1996). Similarly, the health and mortality outcomes of men have been found to deteriorate more than those of women after widowhood (Moon et al. 2011).

In this study, we seek to add to the existing knowledge on the determinants of smoking cessation by studying the gender-specific associations between marital and employment losses and smoking cessation among older adults (i.e. individuals aged 50 and over) in Europe. We use a longitudinal perspective to examine these transitions over a twoyear period (2011-2013).

We hypothesise that potential stressful transitions in life, such as marital and employment losses, could have different effects on the smoking cessation chances of men and women. We also expect that our results for older adults will differ from the findings of previous research that did not focus on this specific age category.

\section{Materials and methods}

\section{Data}

We used panel data on smoking behaviour as well as sociodemographic and health-related variables from wave 4 (2011: baseline) and wave 5 (2013: follow-up) of the Survey of Health, Ageing and Retirement in Europe (SHARE) (Börsch-Supan et al. 2005) for individuals aged 50 and over in the 13 countries covered by the two waves: Austria, Belgium, Czech Republic, Denmark, Estonia, France, Germany, Italy, the Netherlands, Slovenia, Spain, Sweden and Switzerland. We have used the most recent SHARE data, which indeed provided larger sample size than any other pair of SHARE waves. In addition, these waves are only two years apart, which implies that the probability that the respondents experienced more than one marital or employment transition is reduced. However, using both waves provided us with a sample size large enough for the purposes of this study. Of the individuals who participated in both waves $(n=50,332,74.3 \%$ of the individuals at baseline), we selected those who smoked at baseline (20.4\% of the men and $14.1 \%$ of the women). We excluded 110 cases $(1.7 \%)$ with missing values in any of the independent variables resulting in a sample of 3345 men and 3115 women.

\section{Dependent variable}

The dependent variable of this study is smoking cessation over a two-year period (2011-2013). Depending on the answer at the follow-up in 2013 to the question "Do you smoke at the present time?", smokers in 2011 were classified into either ex-smoker (1) or still smoking (0) in 2013.

\section{Independent variables (covariates)}

The main covariates in this analysis were marital and employment losses. In addition we have controlled by age, education, incidence of diseases, country of residence and gender (in the combined model).

Marital status originally had six categories. Three categories represented individuals who were in a union: "married and living together with spouse", "married, living separated from spouse" and "registered partnership"; while the other three categories represented individuals who were not in a union: "never married", "divorced" and "widowed". From the outcome of the two waves, three different transition categories were created based on the assumption that no more than one transition had occurred over the analysed period: "stayed in a union", "became widowed or divorced" (from union to either widowed or divorced) and "not in a union". We excluded from the analysis cases with transitions in a union due to small sample size (35 cases).

Employment status originally had six categories: "retired", "employed or self-employed (including working for family business)", "unemployed and looking for work", "permanently sick or disabled", "homemaker" and "other (rentier, living off of property, student, doing voluntary work)". We re-categorised employment status to account for the transition between waves into: "stayed (self-)employed", "became retired" (from (self-)employed), "stayed retired", "from (self-)employed to unemployed", "sick, disabled, or other unemployed" (which contains individuals who were in any of these states or transiting between them), "stayed homemaker" and a heterogeneous remaining group of "others".

The age at baseline was estimated using the year and the month of birth and the year and the month of the interview, and was included in the models as continuous variable.

Educational attainment was built by SHARE according to the International Standard Classification of Education (ISCED) 1997. Following previous studies (Avendano et al. 2009), the seven categories of this variable were reclassified in three categories: lower secondary school or 
lower (groups 0-2), upper secondary school (group 3) and post-secondary school (groups 4-6).

The detection of a smoking-related disease is one of the main reasons why people quit smoking (Margolis 2013; McKee et al. 2003; van Gool et al. 2007). Chronic conditions (hypertension, high cholesterol, diabetes and lung disease) and major smoking-related diseases (heart attack and cancer) were used to control for disease incidence over the analysed period.

Country of residence was included to control for potential heterogeneity in our sample. Apart from economic and cultural differences, which likely affected the occurrence of employment losses, European countries were subject to different tobacco control policies and to potential changes in these policies. These differences may have affected smoking cessation propensities across countries (Lemmens et al. 2008; Schaap et al. 2008).

\section{Analysis}

Multivariate logistic regressions with smoking cessation as the dependent variable and with marital and employment transitions as independent variables were run for men and women; all controlled for age (as a continuous variable). Additional covariates were added one by one (education, disease incidence and country of residence) in models 2-4, respectively (see Supplementary Tables 1, 2). Model 4, which includes all of the covariates, is the final model presented in the results section. In addition we have run the models for both genders combined (for comparison purposes), adding gender as a control variable. To test if marital and employment losses are differently associated with smoking cessation between men and women we have included the interactions between gender and marital transitions, and between gender and employment transitions.

\section{Results}

In our study sample of 6460 smokers (3345 men and 3115 women) aged 50 and over in 2011, 613 men (18.3\%) and 556 women $(17.8 \%)$ had quit smoking by 2013. Transitions from marriage were more common among women (70 out of $3115 ; 2.2 \%$ ) than among men (49 out of 3345 ; $1.5 \%)$. By contrast, men experienced slightly more employment transitions $(5.4 \%$ retired and $1.5 \%$ became unemployed) than women (4.5 and $1.6 \%$, respectively) (Table 1).

Significant and positive ORs of quitting smoking by age were observed among both genders ( $p$ value $<0.001$ ) (see Online Supplementary Tables 1,2 ). The expected educational gradient in quitting smoking was not found to be significant although the ORs for the highest educational group were larger than the ORs of the reference category: the lowest educated group (men: OR 1.22, $95 \% \mathrm{CI}$ 0.94-1.56; women: OR 1.08, $95 \%$ CI 0.82-1.41). The results for disease incidence indicated that all of the newly diagnosed diseases were positively associated with smoking cessation as compared to not having the disease, but only the incidence of the following diseases was statistically significantly associated with higher smoking cessation ORs: hypertension and heart attack for men and cancer for both men and women. For example, the chances of quitting smoking were twice as high for the individuals with cancer incidence relative to the individuals who did not suffer cancer (OR 1.81, $95 \%$ CI 1.10-2.98, and OR 2.06, $95 \%$ CI 1.22-3.46, for men and women, respectively). Finally, relative to the country with lower share of smokers who stopped by 2013 (Poland for men and Slovenia for women) we found that Italy, the Netherlands, Spain and Sweden had statistically higher ORs of smoking cessation for men, and that Denmark, Germany, Spain and Sweden had higher ORs for women.

\section{The effect of marital losses}

Becoming widowed or divorced was negatively associated with smoking cessation compared to remaining in a union for both men (OR 0.36, $95 \%$ CI 0.14-0.94) and women (OR 0.46, $95 \%$ CI 0.21-0.99) (Table 2). The ORs for remaining not in a union were greater but also negatively associated with smoking cessation among men (OR 0.72, $95 \%$ CI 0.57-0.90). This association was not significant among women although the ORs pointed in the same direction than for men (OR 0.82, $95 \%$ CI 0.67-1.00). To further examine whether our non-significant results were observed due to a relatively small sample size we have performed identical analysis but grouping together data from previous SHARE waves (1-2, 2-4, 4-5), which indeed confirmed that gender differences remained insignificant among older adults (see Online Supplementary Table 3).

\section{The effect of employment losses}

The transitions from employed to unemployed or retirement were not statistically significantly associated with smoking cessation for any of the two genders, although the ORs were above 1. Remaining unemployed (category "sick disabled or other unemployed") was significantly associated with lower ORs among men (OR 0.58, $95 \%$ CI 0.68-0.90) but not among women (OR 1.05, $95 \% \mathrm{CI}$ 0.68-1.63). Stayed retired had a significant negative association with smoking cessation among both men (OR 0.72, $95 \%$ CI 0.53-0.98) and women (OR 0.73, $95 \%$ CI 
Table 1 Background characteristics of smokers in 2011 and percentages of smokers who had stopped smoking by 2013. Source Own estimations based on waves 4 and 5 of SHARE

\begin{tabular}{|c|c|c|c|c|c|c|}
\hline & \multicolumn{2}{|c|}{ Men $(n=3345)$} & \multicolumn{2}{|c|}{ Women $(n=3115)$} & \multicolumn{2}{|c|}{ Total $(n=6460)$} \\
\hline & $\begin{array}{l}\text { Smokers in } \\
2011(n)\end{array}$ & $\begin{array}{l}\% \text { of the smokers who } \\
\text { stopped by } 2013\end{array}$ & $\begin{array}{l}\text { Smokers in } \\
2011(n)\end{array}$ & $\begin{array}{l}\% \text { of the smokers who } \\
\text { stopped by } 2013\end{array}$ & $\begin{array}{l}\text { Smokers in } \\
2011(n)\end{array}$ & $\begin{array}{l}\% \text { of the smokers who } \\
\text { stopped by } 2013\end{array}$ \\
\hline \multicolumn{7}{|l|}{ Marital transitions } \\
\hline Stayed in a union & 2468 & 19.9 & 1762 & 18.7 & 4230 & 19.4 \\
\hline $\begin{array}{l}\text { Became widowed } \\
\text { or divorced }\end{array}$ & 49 & 10.2 & 70 & 11.4 & 119 & 10.9 \\
\hline Not in a union & 828 & 14.0 & 1283 & 17.1 & 2111 & 15.9 \\
\hline \multicolumn{7}{|l|}{ Employment transitions } \\
\hline Stayed employed & 909 & 16.6 & 853 & 15.8 & 1762 & 16.2 \\
\hline Became retired & 179 & 15.6 & 139 & 16.5 & 318 & 16.0 \\
\hline Stayed retired & 1532 & 21.7 & 1223 & 19.1 & 2755 & 20.6 \\
\hline $\begin{array}{l}\text { From employed to } \\
\text { unemployed }\end{array}$ & 51 & 11.8 & 49 & 8.2 & 100 & 10.0 \\
\hline $\begin{array}{l}\text { Sick/disabled or } \\
\text { other unemployed }\end{array}$ & 298 & 10.1 & 199 & 16.6 & 497 & 12.7 \\
\hline Stayed homemaker & 0 & - & 220 & 18.2 & 220 & 18.2 \\
\hline Others & 376 & 17.3 & 432 & 20.1 & 808 & 18.8 \\
\hline \multicolumn{7}{|l|}{ Age (baseline) } \\
\hline $50-59$ & 1458 & 13.7 & 1597 & 14.9 & 3055 & 14.3 \\
\hline $60-69$ & 1307 & 18.5 & 1061 & 18.8 & 2368 & 18.6 \\
\hline $70+$ & 580 & 29.5 & 457 & 26.0 & 1037 & 28.0 \\
\hline \multicolumn{7}{|l|}{ Education (ISCED-97) } \\
\hline $\begin{array}{l}\text { 0-2: Lower } \\
\text { secondary school }\end{array}$ & 1272 & 19.8 & 1188 & 17.7 & 2460 & 18.8 \\
\hline $\begin{array}{l}\text { 3: Upper secondary } \\
\text { school }\end{array}$ & 1277 & 14.6 & 1215 & 18.4 & 2492 & 16.4 \\
\hline $\begin{array}{l}\text { 4-6: Post- } \\
\text { secondary school }\end{array}$ & 796 & 22.0 & 712 & 17.3 & 1508 & 19.8 \\
\hline \multicolumn{7}{|c|}{ Newly diagnosed diseases } \\
\hline Hypertension & 334 & 22.8 & 280 & 21.4 & 614 & 22.1 \\
\hline Cholesterol & 289 & 20.8 & 274 & 18.2 & 563 & 19.5 \\
\hline Diabetes & 114 & 26.3 & 99 & 21.2 & 213 & 23.9 \\
\hline Lung disease & 133 & 23.3 & 132 & 22.0 & 265 & 22.6 \\
\hline Heart attack & 170 & 32.4 & 91 & 22.0 & 261 & 28.7 \\
\hline Cancer & 86 & 29.1 & 73 & 31.5 & 159 & 30.2 \\
\hline \multicolumn{7}{|l|}{ Country } \\
\hline Austria & 358 & 17.9 & 370 & 14.6 & 728 & 16.2 \\
\hline Belgium & 324 & 14.5 & 327 & 14.4 & 651 & 14.4 \\
\hline Czech Republic & 394 & 16.8 & 472 & 15.3 & 866 & 15.9 \\
\hline Denmark & 204 & 17.2 & 200 & 22.5 & 404 & 19.8 \\
\hline Estonia & 638 & 15.7 & 394 & 17.3 & 1032 & 16.3 \\
\hline France & 274 & 11.7 & 246 & 16.7 & 520 & 14.0 \\
\hline Germany & 81 & 22.2 & 73 & 24.7 & 154 & 23.4 \\
\hline Italy & 215 & 27.4 & 191 & 29.3 & 406 & 28.3 \\
\hline Netherlands & 139 & 22.3 & 192 & 15.1 & 331 & 18.1 \\
\hline Slovenia & 145 & 15.2 & 128 & 9.4 & 273 & 12.5 \\
\hline Spain & 236 & 24.6 & 146 & 21.9 & 382 & 23.6 \\
\hline Sweden & 60 & 41.7 & 109 & 30.3 & 169 & 34.3 \\
\hline Switzerland & 277 & 20.2 & 267 & 18.4 & 544 & 19.3 \\
\hline
\end{tabular}


Table 2 Odds ratios $(\mathrm{OR})$ of smoking cessation between 2011 and 2013 the SHARE sample men and women aged 50 and over. Source Own estimation based on SHARE, waves 4 and 5

\begin{tabular}{|c|c|c|c|c|}
\hline & \multicolumn{2}{|c|}{$\operatorname{Men}(n=3345)$} & \multicolumn{2}{|c|}{ Women $(n=3115)$} \\
\hline & OR & CI $95 \%$ & OR & CI $95 \%$ \\
\hline \multicolumn{5}{|l|}{ Marital transitions } \\
\hline \multicolumn{5}{|l|}{ Stayed in a union (ref.) } \\
\hline Became widowed or divorced & 0.359 & $(0.137-0.937)$ & 0.458 & $(0.213-0.987)$ \\
\hline Not in a union & 0.718 & $(0.570-0.904)$ & 0.819 & $(0.668-1.004)$ \\
\hline \multicolumn{5}{|l|}{ Employment transitions } \\
\hline \multicolumn{5}{|l|}{ Stayed (self-)employed (ref.) } \\
\hline Became retired & 0.677 & $(0.426-1.074)$ & 0.845 & $(0.511-1.396)$ \\
\hline Stayed retired & 0.723 & $(0.534-0.979)$ & 0.728 & $(0.530-0.999)$ \\
\hline From (self-)employed to unemployed & 0.624 & $(0.257-1.516)$ & 0.507 & $(0.178-1.446)$ \\
\hline Sick/dis or other unemployed & 0.582 & $(0.376-0.900)$ & 1.053 & $(0.682-1.626)$ \\
\hline Stayed Homemaker & & & 0.786 & $(0.507-1.219)$ \\
\hline Others & 0.885 & $(0.628-1.248)$ & 1.014 & $(0.732-1.405)$ \\
\hline
\end{tabular}

All of the models are controlled by age, education, disease incidence, and country of residence. The results of the covariates are presented in Online Supplementary Tables 1 and 2

"ref." indicates reference categories

The values that are significantly different from 1 (at a $95 \%$ confidence interval) are in bold
0.53-1.00) as compared to those individuals who remained employed throughout the analysed period. All other categories of the variable employment transitions were not significant, and only those for the categories "Sick/disabled or other unemployed" and "others" were (slightly) above 1 among women. Again these insignificant effects seem not to be the result of the sample size (see Online Supplementary Table 3).

\section{The effect of gender}

The association between gender and smoking cessation was not statistically significant (OR 1.08, $95 \%$ CI 0.94-1.24) (Table 3). The results of the interaction terms were not statistically significant at $95 \%$ confidence level, but the interaction between gender and the category "Sick/disabled or other unemployed" was statistically significant at $90 \%$ confidence level (OR 1.80, $95 \%$ CI 0.99-3.27), suggesting women from this category have higher risks of smoking cessation, as compared to men.

\section{Discussion}

\section{Summary of results}

Our analysis of a sample of European adults aged 50 and over indicated that marital and employment losses had different associations with smoking cessation. Over a twoyear follow-up period, our results showed that transitions from being married to being divorced or widowed were significantly associated with lower chances of quitting smoking. Our findings further indicated that transitions to being unemployed or retired were not significantly associated with smoking cessation. We observed no statistically significant differences in these associations between men and women.

\section{Comparison of results}

\section{Marital losses}

Previous studies on the effects of marital transitions on smoking cessation specifically among older adults are scarce. Because age seems to be an essential factor when examining the effects of marital losses on smoking cessation (Grotvedt and Stavem 2005; Jarvis et al. 2013; Umberson et al. 2008; Whitson et al. 2006) we first compare our results with the findings of studies that analysed similar age groups.

We found a negative association between becoming widowed or divorced and smoking cessation in both men and women aged 50 and over. Our results for women seem to be in line with those of a previous study conducted among middle-aged and older women in the USA (Lee et al. 2005), which might indicate that our findings for women may be generalizable for high-income countries. However, our results for men seem to contradict the findings of a US study that showed that changes in smoking behaviour were non-significant in a sample of middle-aged and older US male health professionals (Eng et al. 2005). These different results could be explained by the different 
Table 3 Odds ratios (OR) of smoking cessation between 2011 and 2013 in the SHARE sample men and women aged 50 and over: gender effects. Source Own estimation based on SHARE, waves 4 and 5

\begin{tabular}{|c|c|c|c|c|c|c|}
\hline & \multicolumn{2}{|l|}{ Mod1 } & \multicolumn{2}{|l|}{ Mod2 } & \multicolumn{2}{|l|}{ Mod3 } \\
\hline & OR & CI $95 \%$ & OR & CI $95 \%$ & OR & CI $95 \%$ \\
\hline \multicolumn{7}{|l|}{ Marital transitions } \\
\hline \multicolumn{7}{|l|}{ Stayed in a union (ref.) } \\
\hline Became widowed or divorced & 0.425 & $(0.234-0.771)$ & 0.381 & $(0.147-0.985)$ & 0.426 & $(0.235-0.773)$ \\
\hline Not in a union & 0.765 & $(0.659-0.888)$ & 0.712 & $(0.567-0.893)$ & 0.777 & $(0.669-0.903)$ \\
\hline \multicolumn{7}{|l|}{ Employment transitions } \\
\hline \multicolumn{7}{|l|}{ Stayed (self-)employed (ref.) } \\
\hline Became retired & 0.744 & $(0.530-1.043)$ & 0.746 & $(0.532-1.047)$ & 0.680 & $(0.432-1.069)$ \\
\hline Stayed retired & 0.729 & $(0.587-0.906)$ & 0.732 & $(0.589-0.910)$ & 0.751 & $(0.578-0.974)$ \\
\hline From (self-)employed to unemployed & 0.571 & $(0.291-1.122)$ & 0.572 & $(0.291-1.123)$ & 0.617 & $(0.255-1.494)$ \\
\hline Sick/dis or other unemployed & 0.764 & $(0.563-1.037)$ & 0.770 & $(0.567-1.045)$ & 0.584 & $(0.381-0.895)$ \\
\hline Stayed Homemaker & 0.735 & $(0.493-1.096)$ & 0.747 & $(0.500-1.117)$ & 0.749 & $(0.494-1.135)$ \\
\hline Others & 0.935 & $(0.741-1.181)$ & 0.732 & $(0.589-0.910)$ & 0.751 & $(0.578-0.974)$ \\
\hline \multicolumn{7}{|l|}{ Gender } \\
\hline \multicolumn{7}{|l|}{ Men (ref.) } \\
\hline Women & 1.079 & $(0.939-1.240)$ & 1.036 & $(0.876-1.224)$ & 1.051 & $(0.810-1.362)$ \\
\hline Women $*$ became widowed or divorced & & & 1.223 & $(0.362-4.134)$ & & \\
\hline Women $*$ Not in a union & & & 1.138 & $(0.842-1.538)$ & & \\
\hline Women * Became retired & & & & & 1.230 & $(0.631-2.397)$ \\
\hline Women $*$ Stayed retired & & & & & 0.932 & $(0.674-1.288)$ \\
\hline Women $*$ From (self-)employed to unemployed & & & & & 0.832 & $(0.211-3.278)$ \\
\hline Women $*$ Sick/dis or other unemployed & & & & & 1.801 & $(0.991-3.273)$ \\
\hline \multicolumn{7}{|l|}{ Women $*$ Stayed Homemaker } \\
\hline Women * Others & & & & & 1.108 & $(0.706-1.737)$ \\
\hline
\end{tabular}

All of the models are controlled by age, education, disease incidence, and country of residence

"ref." indicates reference categories

The values that are significantly different from 1 (at a $95 \%$ confidence interval) are in bold

outcome measures of the two studies: i.e. changes in smoking behaviour versus smoking cessation.

Comparing our results to previous findings for adult populations (Nystedt 2006), the negative association between marital loss and smoking cessation is consistent and seems to persist throughout the adult life course. Our finding of a non-significant gender difference in this association is also consistent with those of previous research that investigated the association between marital transitions and smoking cessation (Nystedt 2006) or the association between interpersonal loss (including death of the spouse) and smoking cessation (McKee et al. 2003) at adult ages.

\section{Employment losses}

In terms of employment losses, the non-significant differences in smoking cessation we observed between individuals who did or did not become unemployed are similar to those found in an earlier study on the effects of involuntary job loss on smoking cessation among older workers (Falba et al. 2005). Likewise, insignificant results were found in a sample of adult Germans (Schunck and Rogge 2012).

Previous studies that looked at the effects of the transition to retirement on smoking cessation, reported mixed results: one UK study reported a positive effect (Lang et al. 2007) while another, from the USA, found no significant effect (Midanik et al. 1995). Our finding of a non-significant association between entering retirement and smoking cessation among both men and women, which was derived from a large European sample, shows that the association is predominantly not significant.

Our finding that gender differences in terms of employment transitions were non-significant cannot be compared to the results of previous studies, because of the absence of gender-specific studies. It should be noted that although we do not see an effect of gender at $95 \%$ confidence level, for "sick/dis or other unemployed" we do 
find an effect of gender at $90 \%$ confidence level. This observation is important because previous studies that did not examine gender differences found that unemployed adults had lower chances of smoking cessation than employed adults (De Vogli and Santinello 2005; Giordano and Lindstrom 2011; Kriegbaum et al. 2011). It appears that these results were largely driven by men. The above example indicates that gender-specific analysis can be essential for understanding the mechanisms that underlie the aggregated results of some employment transitions.

\section{Explanation of results}

Marital losses seem to have had important effects on smoking cessation for both men and women, and at all adult ages. At older ages the effects of marital losses were larger and more robust than the effects of employment losses. This finding suggests that among both men and women the lack of a spouse was a greater handicap for smoking cessation than the lack of employment.

Our results also showed that the associations between marital and employment losses and smoking cessation did not differ by gender. Therefore, the hypothesised underlying mechanisms of gender differences mentioned in the introduction (stress arising from different types of events combined with differences in coping mechanisms, and marriage having stronger protective effects on unhealthy behaviours among men than among women) were not sufficiently strong among older adults to have resulted in gender differences in smoking cessation. This finding seems to be in line with a previous result showing that gender differences in the protective effect of marriage for mortality did not exist at old ages (Manzoli et al. 2007). Thus, some mechanisms related to gender differences at all adult ages do not seem to apply at older ages.

The observation that our results are more in line with previous results for adult ages is quite unexpected. Previous research reported that smoking cessation rates were higher among older than younger adults (Jarvis et al. 2013). Similarly, we found that the variable age was positively associated with smoking cessation (Table 3). However, our results also showed that marital and employment losses had similar influences on smoking cessation, regardless of the age group analysed. It may be the case that that the effects on quitting smoking of the stress that accompanied these transitions were similar across individuals of all adult ages.

\section{Evaluation of data and methods}

In this study we used European data for 13 countries to examine potential determinants of smoking cessation among older adults. So far, relatively little research has been carried out on the topic of smoking cessation among older workers and retirees, and to our knowledge this is the first study that has examined this issue for the European context as a whole.

Our study has some limitations. First, we were not able to establish causality between transitions in marital or employment status and smoking cessation. However, it is highly probable that marital and employment losses have an impact on smoking cessation via psychosocial stress (De Vogli and Santinello 2005; Falba et al. 2005; Johnson and Wu 2002; McKee et al. 2003), and it seems unlikely that these effects go in the opposite direction. Second, we used data from two periods of time (2011 and 2013), assuming that no more than one transition had occurred in terms of marriage and employment. Although several marital and employment transitions may have occurred, it is unlikely that individuals would have experienced multiple marriage and employment transitions within the relatively short two-year period. Third, our results may be influenced by other, stressful, events in life with an effect on smoking cessation. However, because we selected a relatively short period of time between the waves, the chances of this are lower compared to a longer period of time between the waves. Finally, due to data limitations we could not control for other factors that have been shown to contribute to smoking cessation, such as the presence of smokers in the household (Chandola et al. 2004), the number of cigarettes smoked per day and the onset of smoking behaviour (Broms et al. 2004). Because our results for marital and employment transitions changed only a little when we included variables that are known to be strongly associated with smoking cessation (i.e. the incidence of various diseases), we expect that our results will be proven to be robust when other, less important variables are included.

\section{Conclusion}

In conclusion, our results indicate that in high-income countries the loss of a spouse has clear negative effects on smoking cessation not only at adult ages, but also specifically among adults aged 50 and over. Negative effects of transitions to unemployment or retirement on smoking cessation could not be demonstrated; a finding that is partly in line with the results at all adult ages. The absence of statistically significant gender differences in the observed associations for marital and employment losses seems to indicate that among adults aged 50 and over, the hypothesised underlying mechanisms differ little by gender. Health interventions should take into account the finding that the groups with lower chances of quitting smoking are affected by marital losses, irrespective of gender. 
Acknowledgments This research was initiated through the European Doctoral School of Demography (2013/14) at the Warsaw School of Economics, which the first author attended with a fellowship from the Centre for Demographic Studies. The research was finalised at the Population Research Centre, University of Groningen, where the first author holds a Ph.D. position within the research project "Smoking, alcohol and obesity - ingredients for improved and robust mortality projections", which was financed by Dutch Scientific Research (NWO), Grant no. 452-13-001. This paper uses data from SHARE wave 4 release 1.1.1, as of March 28th 2013(DOI: 10.6103/SHARE. w4.111) and SHARE wave 1 and 2 release 2.6.0, as of November 29 2013 (DOI: 10.6103/SHARE.w1.260 and 10.6103/SHARE.w2.260). The SHARE data collection has been primarily funded by the European Commission through the 5th Framework Programme (Project QLK6-CT-2001-00360 in the thematic programme Quality of Life), through the 6th Framework Programme (projects SHARE-I3, RII-CT2006-062193, COMPARE, CIT5- CT-2005-028857, and SHARELIFE, CIT4-CT-2006-028812) and through the 7th Framework Programme (SHARE-PREP, $\mathrm{N}^{\circ} 211909$, SHARE-LEAP, $\mathrm{N}^{\circ} 227822$ and SHARE M4, $\mathrm{N}^{\circ}$ 261982). Additional funding from the U.S. National Institute on Aging (U01 AG09740-13S2, P01 AG005842, P01 AG08291, P30 AG12815, R21 AG025169, Y1-AG-4553-01, IAG BSR06-11 and OGHA 04-064) and the German Ministry of Education and Research as well as from various national sources is gratefully acknowledged (see www.share-project.org for a full list of funding institutions).

\section{Compliance with ethical standards}

\section{Conflicts of interest None.}

Open Access This article is distributed under the terms of the Creative Commons Attribution 4.0 International License (http://crea tivecommons.org/licenses/by/4.0/), which permits unrestricted use, distribution, and reproduction in any medium, provided you give appropriate credit to the original author(s) and the source, provide a link to the Creative Commons license, and indicate if changes were made.

\section{References}

Avendano M, Glymour MM, Banks J, Mackenbach JP (2009) Health disadvantage in US adults aged 50 to 74 years: a comparison of the health of rich and poor Americans with that of Europeans. Am J Public Health 99(3):540-548. doi:10.2105/AJPH.2008. 139469

Blakely T, van der Deen FS, Woodward A, Kawachi I, Carter K (2014) Do changes in income, deprivation, labour force status and family status influence smoking behaviour over the short run? panel study of 15,000 adults. Tob Control 23(e2):e106e113. doi:10.1136/tobaccocontrol-2012-050944

Börsch-Supan A, Hank K, Jürges H (2005) A new comprehensive and international view on ageing: introducing the 'Survey of health, ageing and retirement in europe'. Eur J Ageing 2(4):245-253

Broms U, Silventoinen K, Lahelma E, Koskenvuo M, Kaprio J (2004) Smoking cessation by socioeconomic status and marital status: the contribution of smoking behavior and family background. Nicot Tob Res 6(3):447-455. doi:10.1080/1462220041000169 6637

Burns DM (2000) Primary prevention, smoking, and smoking cessation: implications for future trends in lung cancer prevention. Cancer 89(11 Suppl):2506-2509. doi:10.1002/10970142(20001201)89:11+<2506:AID-CNCR33>3.3.CO;2-\#
Chandola T, Head J, Bartley M (2004) Socio-demographic predictors of quitting smoking: how important are household factors? Addiction 99(6):770-777. doi:10.1111/j.1360-0443.2004.00756.x

De Vogli R, Santinello M (2005) Unemployment and smoking: does psychosocial stress matter? Tob Control 14(6):389-395

Doll R, Peto R, Boreham J, Sutherland I (2004) Mortality in relation to smoking: 50 years' observations on male British doctors. BMJ 328(7455):1519. doi:10.1136/bmj.38142.554479.AE

Eng PM, Kawachi I, Fitzmaurice G, Rimm EB (2005) Effects of marital transitions on changes in dietary and other health behaviours in US male health professionals. J Epidemiol Community Health 59(1):56-62

Ensminger ME, Celentano DD (1990) Gender differences in the effect of unemployment on psychological distress. Soc Sci Med 30(4):469-477

Falba T, Teng HM, Sindelar JL, Gallo WT (2005) The effect of involuntary job loss on smoking intensity and relapse. Addiction 100(9):1330-1339

Giordano GN, Lindstrom M (2011) The impact of social capital on changes in smoking behaviour: a longitudinal cohort study. Eur J Public Health 21(3):347-354. doi:10.1093/eurpub/ckq048

Grotvedt L, Stavem K (2005) Association between age, gender and reasons for smoking cessation. Scand J Public Health 33(1):72-76

Henkens K, van Solinge H, Gallo WT (2008) Effects of retirement voluntariness on changes in smoking, drinking and physical activity among dutch older workers. Eur J Public Health 18(6):644-649. doi:10.1093/eurpub/ckn095

Janzon E, Engstrom G, Lindstrom M, Berglund G, Hedblad B, Janzon L (2005) Who are the "quitters"? a cross-sectional study of circumstances associated with women giving up smoking. Scand J Public Health 33(3):175-182

Jarvis MJ, Cohen JE, Delnevo CD, Giovino GA (2013) Dispelling myths about gender differences in smoking cessation: population data from the USA, Canada and Britain. Tob Control 22(5):356-360. doi:10.1136/tobaccocontrol-2011-050279

Johnson DR, Wu J (2002) An empirical test of crisis, social selection, and role explanations of the relationship between marital disruption and psychological distress: a pooled time-series analysis of four-wave panel data. J Marriage Fam 64(1):211-224

Kendler KS, Thornton LM, Prescott CA (2001) Gender differences in the rates of exposure to stressful life events and sensitivity to their depressogenic effects. Am J Psychiatry 158(4):587-593

Kessler RC, McLeod JD (1984) Sex differences in vulnerability to undesirable life events. Am Sociol Rev 49:620-631

Kriegbaum M, Larsen AM, Christensen U, Lund R, Osler M (2011) Reduced probability of smoking cessation in men with increasing number of job losses and partnership breakdowns. J Epidemiol Community Health 65(6):511-516. doi:10.1136/jech. 2009.100446

Lang IA, Rice NE, Wallace RB, Guralnik JM, Melzer D (2007) Smoking cessation and transition into retirement: analyses from the english longitudinal study of ageing. Age Ageing 36(6):638-643

Lee S, Cho E, Grodstein F, Kawachi I, Hu FB, Colditz GA (2005) Effects of marital transitions on changes in dietary and other health behaviours in US women. Int J Epidemiol 34(1):69-78. doi:10.1093/ije/dyh258

Lemmens V, Oenema A, Knut IK, Brug J (2008) Effectiveness of smoking cessation interventions among adults: a systematic review of reviews. Eur J Cancer Prev 17(6):535-544. doi:10. 1097/CEJ.0b013e3282f75e48

Lillard LA, Panis CW (1996) Marital status and mortality: the role of health. Demography 33(3):313-327

Lim SS, Vos T, Flaxman AD, Danaei G, Shibuya K, Adair-Rohani H, Memish ZA (2012) A comparative risk assessment of burden of 
disease and injury attributable to 67 risk factors and risk factor clusters in 21 regions, 1990-2010: a systematic analysis for the global burden of disease study 2010. Lancet 380(9859):2224-2260. doi:10.1016/S0140-6736(12)61766-8

Manzoli L, Villari P, Pirone GM, Boccia A (2007) Marital status and mortality in the elderly: a systematic review and meta-analysis. Soc Sci Med 64(1):77-94

Margolis R (2013) Educational differences in healthy behavior changes and adherence among middle-aged Americans. J Health Soc Behav 54(3):353-368. doi:10.1177/0022146513489312

McKee SA, Maciejewski PK, Falba T, Mazure CM (2003) Sex differences in the effects of stressful life events on changes in smoking status. Addiction 98(6):847-855

Midanik LT, Soghikian K, Ransom LJ, Tekawa IS (1995) The effect of retirement on mental health and health behaviors: the Kaiser Permanente Retirement Study. J Gerontol Ser B 50(1):S59-S61

Moon JR, Kondo N, Glymour MM, Subramanian SV (2011) Widowhood and mortality: a meta-analysis. PLoS ONE 6(8):e23465. doi:10.1371/journal.pone.0023465

Nystedt P (2006) Marital life course events and smoking behaviour in sweden 1980-2000. Soc Sci Med 62(6):1427-1442

Osler M, Prescott E (1998) Psychosocial, behavioural, and health determinants of successful smoking cessation: a longitudinal study of Danish adults. Tob Control 7(3):262-267

Osler M, Prescott E, Godtfredsen N, Hein HO, Schnohr P (1999) Gender and determinants of smoking cessation: a longitudinal study. Prev Med 29(1):57-62. doi:10.1006/pmed.1999.0510

Schaap MM, Kunst AE, Leinsalu M, Regidor E, Ekholm O, Dzurova D, Mackenbach JP (2008) Effect of nationwide tobacco control policies on smoking cessation in high and low educated groups in 18 european countries. Tob Control 17(4):248-255. doi:10. $1136 /$ tc. 2007.024265

Schone BS, Weinick RM (1998) Health-related behaviors and the benefits of marriage for elderly persons. Gerontologist 38(5):618-627

Schunck R, Rogge BG (2012) No causal effect of unemployment on smoking? A german panel study. Int $J$ Public Health 57(6):867-874. doi:10.1007/s00038-012-0406-5

Taylor DH Jr, Hasselblad V, Henley SJ, Thun MJ, Sloan FA (2002) Benefits of smoking cessation for longevity. Am J Public Health 92(6):990-996

Thomas C, Benzeval M, Stansfeld SA (2005) Employment transitions and mental health: an analysis from the british household panel survey. J Epidemiol Community Health 59(3):243-249

Umberson D, Liu H, Reczek C (2008) Stress and health behaviour over the life course. Adv Life Course Res 13:19-44

van den Putte B, Yzer MC, Brunsting S (2005) Social influences on smoking cessation: a comparison of the effect of six social influence variables. Prev Med 41(1):186-193

van Gool CH, Kempen GI, Penninx BW, Deeg DJ, van Eijk JT (2007) Chronic disease and lifestyle transitions: results from the longitudinal aging study amsterdam. J Aging Health 19(3):416-438

Whitson HE, Heflin MT, Burchett BM (2006) Patterns and predictors of smoking cessation in an elderly cohort. J Am Geriatr Soc 54(3):466-471 